\title{
Aspegilose visceral causado por Aspergillusflavus em Marreco Carolina (Aix sponsa)
}

\author{
Visceral aspergillosis caused by Aspergillus flavus in Wood duck (Aix sponsa)

\section{Guilherme Augusto Marietto-Gonçalves ${ }^{1} \&$ Raphael Lucio Andreatti Filho $^{2}$}

\section{RESUMO}

A aspergilose é uma doença que acomete o trato respiratório causada por fungos do gênero Aspergillus, um agente saprófito que se dissemina pelo ar. O presente artigo relata a ocorrência de aspergilose visceral causada por Aspergillus flavus em Marreco Carolina (Aix sponsa) atendido no Laboratório de Ornitopatologia do Hospital Veterinário da Faculdade de Medicina Veterinária e Zootecnia da Universidade Estadual Paulista, campus Botucatu-SP.

Descritores: Aspergilose, Aspergillus flavus, ornitopatologia.

\section{ABSTRACT}

Aspergillosis it is a diseases that attack the respiratory tract caused by fungy of the genus Aspergillus, one saprohytal agent that is disseminated for the air. The present article related the occurrence of cisceral aspergillosis caused by Aspergillus flavus in Wood duck (Aix sponsa) attended in the Ornitopathogy Laboratory of the Veterinary Hospital of the Veterinary Medicine and Zootecny Faculdad of the Paulista State University, campus Botucatu-SP (FMVZ-UNESP/Botucatu-SP).

Key words: Aspergillosis, Aspergillus flavus, ornitophatology. 


\section{INTRODUÇÃO}

A aspergilose é causada por fungos do gênero Aspergillus, da família Moliniaceae, ordem Moniliales, entre os quais, A. fumigatus, espécie comumente isolada em aves, mas que pode acometer qualquer espécie, doméstica ou selvagem [1,2,5].

O Aspergillus se dissemina no ar e é muito encontrado na biota anemófila em todo o mundo. Os seus propágulos fúngicos são bastante termotolerantes, o que facilita sua viabilidade em ambientes inóspitos. É um fungo sapróbio e ubiqüitário, encontrado no solo úmido, vegetação morta e em sementes [3], e a ocorrência da aspergilose está relacionada aos ambientes com más condições de higiene [4].

A aspergilose é uma doença secundária favorecida por debilidade, imunodepressão e por manejo inadequado. Pode apresentar duas formas distintas: aguda e crônica. É predominantemente uma doença respiratória, mas pode apresentar uma forma ocular, nervosa, e com menos frequiência à forma cutânea [1,2].

A forma aguda é uma doença respiratória fatal onde se observa exsudatos mucóides brancos por todo o trato respiratório, congestão pulmonar, aerossaculite e focos de pneumonia nodular circundados por hiperemia. A forma crônica é caracterizada por granulomas com múltiplos nódulos disseminadas em pulmão e sacos aéreos, podendo ser encontrados também em regiões periféricas destes. Os nódulos variam de tamanho, podendo ser de coloração branca ou amarelada, e se apresentar como massas caseosas-granulomatosas esverdeadas com colônias do fungo [2].

Clinicamente apresenta sinais vagos, o que dificulta o diagnóstico da doença. Por se apresentar de forma aguda, a morte subida é o sinal mais comum, mas pode se observar em alguns casos dispnéia, anorexia, letargia, depressão, emaciação e até alterações nervosas [2,5]. A análise hematológica pode auxiliar no diagnóstico, onde se pode observar leucocitose, heterofilia, monocitose e linfopenia, diminuição da proteína sérica total e das globulinas e ocasionalmente anemia não-regenerativa [2]. A melhor forma de diagnosticar a aspergilose é associar sinais clínicos com isolamento dos fungos de secreções ou de órgãos [6].

\section{RELATO DE CASO}

Um Marreco Carolina (Aix sponsa), ordem Anseriformes, família Anatidae, espécie exótica à fauna brasileira, fêmea, pesando $700 \mathrm{~g}$, com aproximadamente 1,5 ano, com histórico de agressões por parte do bando e após estes episódios passou a apresentar apatia, dificuldade respiratória, letargia e anorexia, tendo sido medicada com $0,25 \mathrm{ml}$ IM de Enrofloxacina a 2,5\% (BID) por 7 dias, 0,3ml IM de Dexametasona (SID) por 3 dias e $0,4 \mathrm{ml}$ IM de vitamina B12 (SID) por um médico veterinário autônomo. De início a ave apresentou sensível melhora, porém após um dia de tratamento passou a apresentar gradativamente paresia de membros, sendo encaminhada uma semana depois para o Laboratório de Ornitopatologia do Hospital Veterinário da FMVZ-UNESP/ Botucatu-SP.

Durante o exame físico observou-se apatia profunda sem resposta a estímulos externos (som e luz). Coletou-se sangue para a realização de exame hematológico e sorológico, tendo-se observado uma discreta linfopenia e resultado negativo para Mycoplasma gallisepticum e M. synoviae, analisado por soroaglutinação rápida em placa. Radiologicamente não se observou nenhuma alteração em estruturas ósseas. Durante o procedimento a ave faleceu, sendo encaminhada para exame necroscópico.

$\mathrm{Na}$ necropsia observou-se uma massa, com aproximadamente $1 \mathrm{~cm}$ de diâmetro, entre esôfago e traquéia, na entrada da cavidade celomática, acima da base do coração, pequenos nódulos esbranquiçados em sacos aéreos e um foco de pneumonia em região pulmão direito (Figura 1), não se observando alterações em demais órgãos e estruturas. Ao se examinar a massa observada entre traquéia e esôfago, observou-se à presença de colônias fúngicas de coloração esverdeada em seu interior (Figura 2).

Foram obtidas amostras do foco de pneumonia, da massa encontrada em esôfago e de nódulos em sacos aéreos e após cultivo em Agar Sabouraud Dextrosado, a $37^{\circ} \mathrm{C}$ por cinco dias, conforme Richard \& Beneke [6], isolou-se Aspergillus flavus, caracterizado mediante o aspecto macroscópico da colônia e microscópico através da coloração das hifas com Azul de lactofenol [1].

\section{DISCUSSÃO}

Os achados de necropsia associados ao isolamento microbiológico foram conclusivos para o diagnóstico de aspergilose. É possível que a situação 


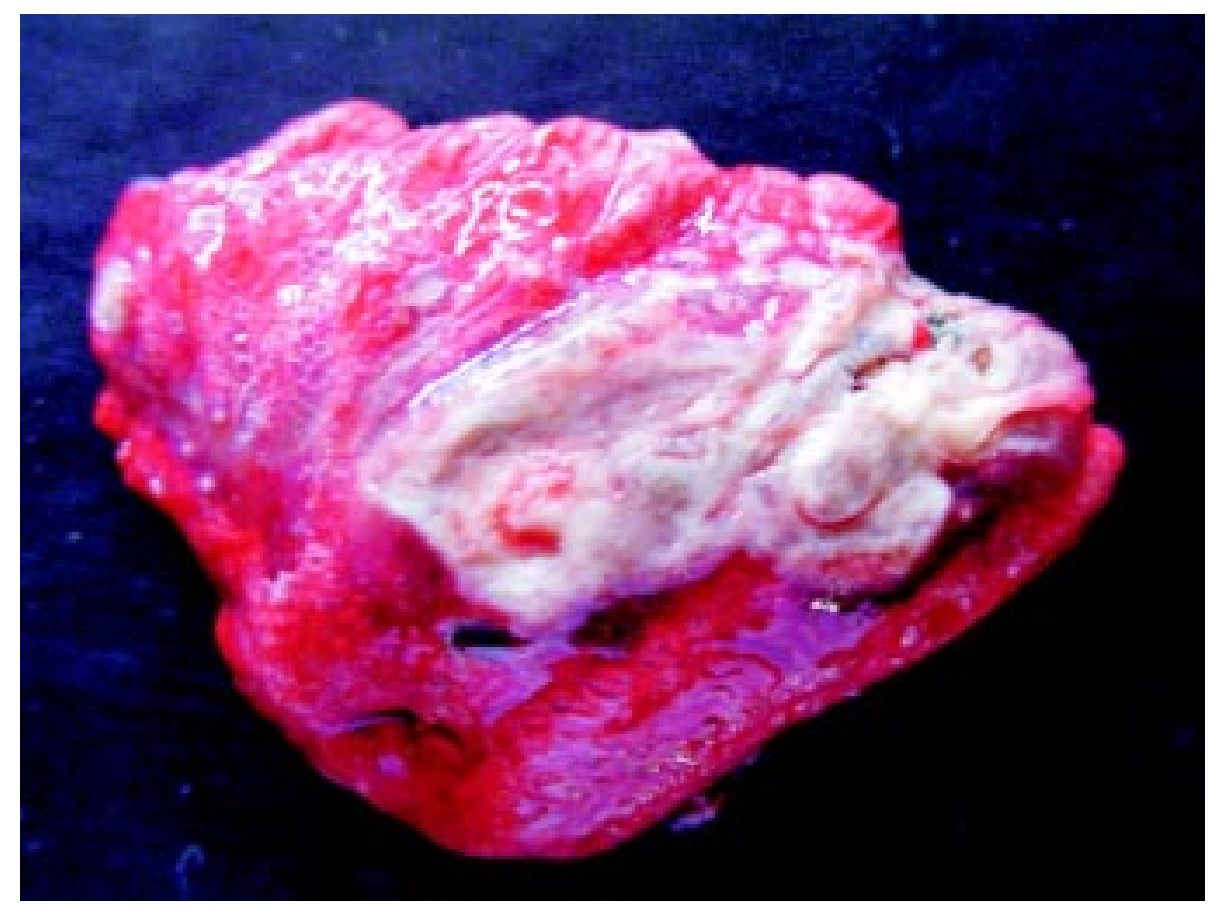

Figura 1. Foco de pneumonia em região caudo-dorsal do pulmão direito.

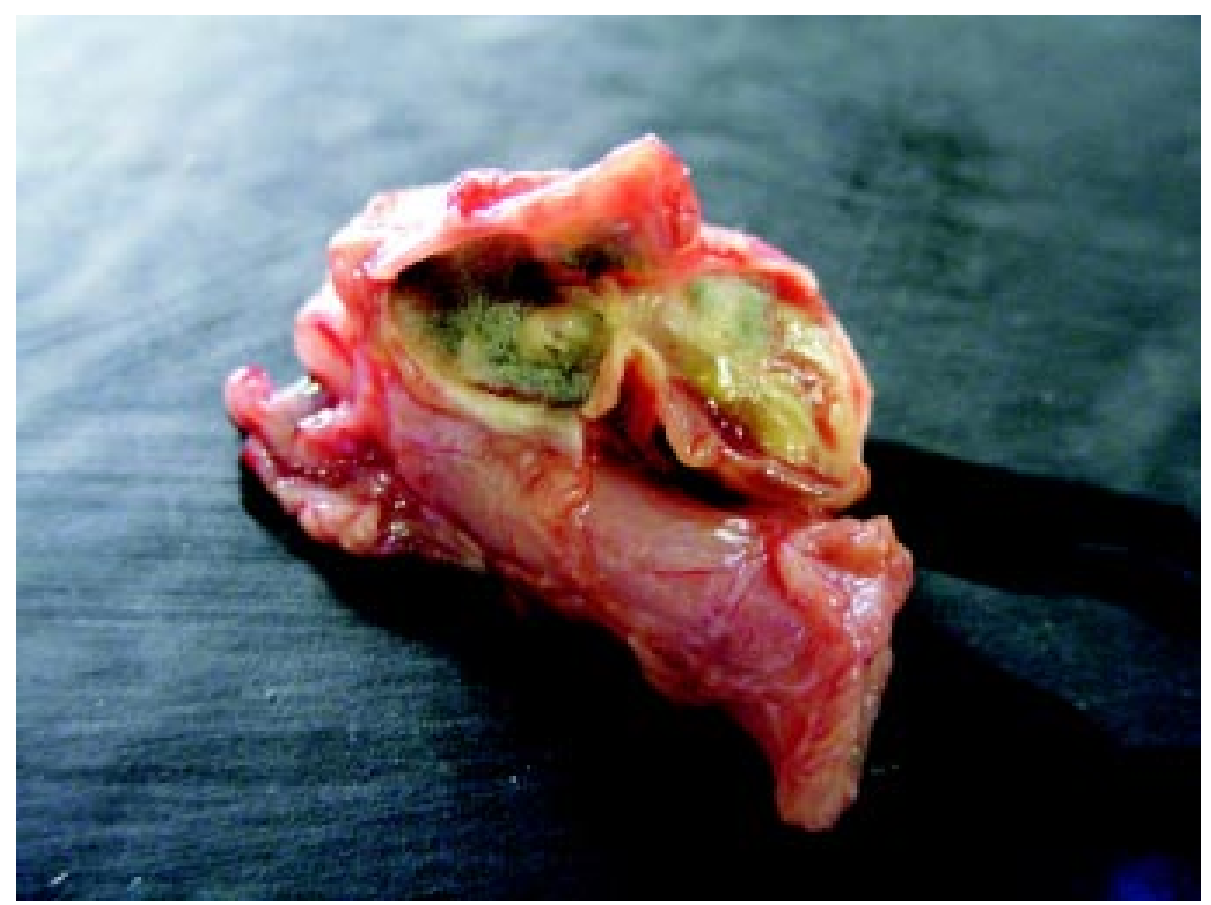

Figura 2. Massa esofágica em região dorsal com conteúdo aveludado esverdeado encontrado no exame necroscópico.

de estresse, devido à agressão das demais aves da propriedade, somado com a aplicação de antibióticos, em conjunto com terapia antiinflamatória a base de corticóides, e um ambiente com de má qualidade sanitária tenha propiciado a ocorrência da aspergilose.
Ao contrário do que se encontrou na literatura, isolouse nesse caso A. flavus, onde também não se encontrou relatos de lesões causadas por esta espécie em outros órgãos que não seja no trato respiratório na literatura atual. 


\section{REFERÊNCIAS}

1 Andreatti Filho R.L. 2006. Doenças fúngicas. In: Andreatti Filho R.L. (Ed). Saúde Aviária e Doenças. São Paulo: Roca, pp.236-245.

2 Campbell T.W. 1896. Bacterial Diseases. In: Harrison G.J \& Harrison L.R. (Eds). Clinical Avian Medicine and Surgery. Philadelphia: W.B. Saunders Company, pp.464-471.

3 Friend M. \& Franson C. 1999. Field Manual of Wildlife Diseases. Madison: Biological Resources Division, p.426.

4 Garcia M.E. \& Blanco J.L. 2000. Principales enfermidades fúngicas que afectam los animales domésticos. Revista Iberoamericana de Micología. 17: S2-S7.

5 Keymer I.F. 1982. Mycoses. In: Petrak M.L. (Ed). Diseases of Cage and Aviary Birds. 2nd edn. Philadelphia: Lea \& Fabiger, pp.599-605.

6 Richard J.L. \& Beneke E.S. 1989. Mycoses and Mycotoxicoses. In: Chairman H.G.P. et al. A Laboratory Manual for the Isolation and Identification of Avian Pathogens. 3rd edn. Iowa: The American Association of Avian Pathologists, pp.70-76. 